\title{
Profiles of public and private autism-specific schools in Gauteng
}

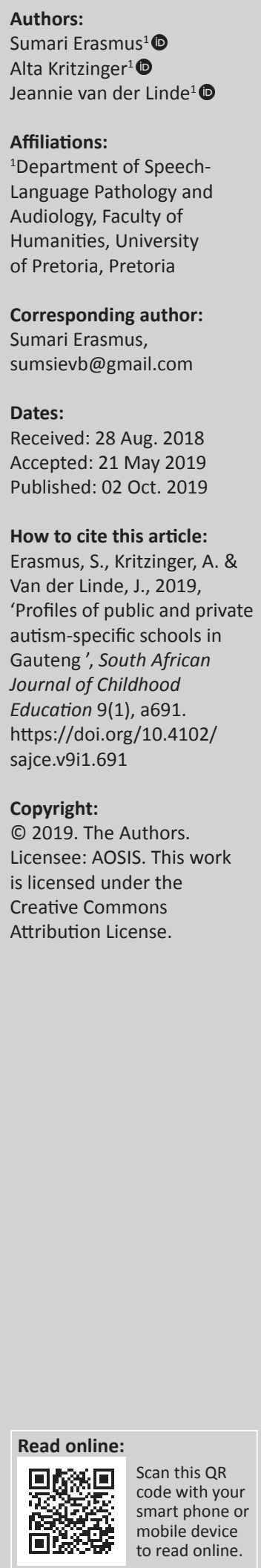

Background: Despite inclusive education (IE) policies and legislation being introduced in South Africa (SA), learners with autism spectrum disorder (ASD) are still placed in autismspecific public and private schools. Limited data are available on who makes use of the two different types of schools. Results may provide information on the profiles and education of learners with ASD in Gauteng schools.

Aim: A quantitative, cross-sectional, comparative research design was used to compare the profiles of autism-specific public with autism-specific private schools and learners in Gauteng Province.

Setting: The research was conducted in two autism-specific public and two private schools.

Methods: Two survey questionnaires were used to collect data from four principals of two autism-specific public and two autism-specific private schools and 150 caregivers of learners attending the participating schools.

Results: Results showed that because of their size autism-specific public schools make a significant contribution to the education of learners with ASD in Gauteng, compared to autismspecific private schools. Autism-specific public schools offer more therapy services than the autism-specific private schools, despite lower fees than autism-specific private schools. Significantly more black learners attend autism-specific public schools than autism-specific private schools. Regardless of the differences in population groups across the participating schools, the mean age when caregivers became concerned about their child's development was similar across the two types of schools. Learners enrolled at the autism-specific private schools were diagnosed with ASD earlier than learners enrolled at the autism-specific public schools. Also, they commenced school earlier than the learners in the autism-specific public schools. Lastly, three of the four principals expressed a preference that learners with ASD be placed in autism-specific schools.

Conclusion: The results highlight the need to raise awareness of ASD symptoms among parents with young children in all communities and to determine the barriers that hinder IE for learners with ASD in SA.

Keywords: autism-specific schools; Gauteng; inclusive education; learners; private and public education.

\section{Introduction}

In South Africa (SA), educational placement for learners with autism spectrum disorder (ASD) is a pertinent topic in light of the inclusive education (IE) policy recommending that all learners should be educated in the least restrictive environment (Department of Education [DoE] 2001). The current state of education in SA could be attributed to the legacy of apartheid education policies (1948-1994) (Engelbrecht 2006:254). During the 46 years of apartheid, learners with disabilities were segregated twice according to their population group and disability (Donohue \& Bornman 2014:2; Engelbrecht 2006:254). Under apartheid, white learners who experienced barriers to learning received high-quality special education with adequate resources and well-trained teachers. In contrast, black, Indian and mixed race children were educated in separate facilities from white learners and received relatively low-quality education from poorly trained teachers (DoE 2001). The Bill of Rights, included in the Constitution of the Republic of South Africa (Act No. 108 of 1996), declares that all South African citizens have the right to basic education, regardless of the barriers to learning. Key education legislation and policies introduced since 1994 simultaneously abolished discrimination and introduced IE (DoE 1995, 1996, 1997, 2010a, $2010 \mathrm{~b}, 2014)$. Inclusive education is a system where the diverse needs of all learners are addressed 
by reducing the barriers to and within the learning environment (DoE 2001). Therefore, the intention was to follow the same trend of IE as in most other countries where learners who experience barriers are included in mainstream classes (DoE 2001; Engelbrecht 2006:260; Jones \& Frederickson 2010:1102; Waddington \& Reed 2017:139).

Barriers to the effective implementation of IE include a lack of teacher capacity, limited financial resources, poverty and the negative attitudes towards disability in general (Bornman \& Rose 2010:7; Engelbrecht 2006:255). These barriers may contribute to certain discomfort about the concept of inclusion in SA (Donohue \& Bornman 2014:3). Furthermore, although the IE policy in SA (DoE 2001) recommends that learners with barriers to learning should be included in mainstream schooling, learners with ASD are still being segregated in public and private special schools (DoE 2015; Pillay, Duncan \& De Vries 2017; Statistics South Africa 2014). One of the reasons may be because learners with ASD experience increased difficulty adapting to mainstream school settings because their behaviour is often noticeably different from that of typically developing children (Whitman 2004). Another reason may be that the three levels of severity of ASD, as described by the Diagnostic and Statistical Manual of Mental Disorder Fifth Edition (DSM-5), may differ significantly and therefore require various levels of support (American Psychiatric Association [APA] 2013). For example, a learner with ASD with a severity level of three requires 'very substantial support' (APA). These learners require very substantial support with social communication skills as they have severe deficits in verbal and nonverbal communication. Furthermore, they require very substantial support in their restricted and repetitive behaviours as they may experience consistent difficulty in coping with changes and inflexible behaviour (APA). However, a learner with ASD with level 2 severity requires considerable support because they present with marked deficits in verbal and nonverbal social communication and difficulty in coping with changes as their restricted and repetitive behaviour interfere with their functioning in various contexts (APA). Lastly, a learner with ASD with only level 1 severity requires minimal support. Should the learner not receive the necessary support, deficits in social communication may cause significant impairments, while inflexibility of behaviour may also cause interference with functioning in one or more contexts (APA). It is therefore important to ensure that learners with ASD are placed in a school meeting their support needs.

Currently, there are only a few autism-specific public schools in SA. Over the last 2 years, however, the Gauteng Department of Education (GDE) has opened 18 new ASD units in schools for learners with special educational needs (LSEN) (Evans 2016) to reduce extensive waiting lists (Clasquin-Johnson \& Clasquin-Johnson 2018:4). It therefore seems that the GDE is perpetuating segregated placement for learners with ASD even though legislation and policy recommend inclusion in mainstream schools (DoE 2001; Evans 2016). According to Clasquin-Johnson and Clasquin-Johnson (2018:4), there are still many learners with ASD who are not benefiting from early childhood education (ECE) (age: birth to 9 years) as they are waiting for school placement. Also, the ECE sector does not have the capacity for early screening and intervention as personnel are either under- or unqualified (Human Sciences Research Council [HSRC] 2009). A further disadvantage of the autism-specific public schools is that they are largely limited to the urban middle- to high-income communities (Autism South Africa [ASA] n.d.), thereby excluding children with ASD from rural areas (Saloojee et al. 2006:233). As a consequence, there has been an increase in homeschooling children with ASD (Nhlapo 2018) as well as an increase in private schools accommodating learners with ASD and other developmental disabilities (ASA n.d.). While private schools are more costly than public schools, they provide an educational solution for families with limited options because of the lack of space in autism-specific public schools in SA. However, limited research has been conducted on the profiles of autism-specific schools and their learners in SA. When investigating learners with ASD in SA, it is clear that both public and private special schools should be considered. Results may provide information on the education of learners with ASD in Gauteng Province schools. The researchers expect that the comparison will reveal not only critical differences between the two types of schools, but also similarities. Because of limited space in autism-specific public schools and minimal progress in the implementation of IE for learners with ASD, there may also be similarities in learner profiles across the different types of schools.

\section{Research methods}

\section{Aim and design}

A quantitative, cross-sectional, comparative research design was used to compare the profiles of autism-specific public with autism-specific private schools and learners in Gauteng Province.

\section{Setting}

Although there are no official statistics available on how many learners with ASD are being accommodated for in autism-specific and mainstream schools, it seems that the majority school-going age children with ASD are accommodated in autism-specific schools (Evans 2016). These schools are therefore described as 'population-rich settings' (Evans 2016). Before the data collection, the researcher consulted ASA and requested a list of all the autism-specific public (government-funded) and private (independent) schools in Gauteng Province. Only autismspecific schools which existed for more than 10 years in the province were selected for the study because they have accumulated experience and are regarded as resource centres for training and research (ASA n.d.). At the time of data collection, there were three autism-specific private and three autism-specific public schools in Gauteng Province, but only two autism-specific private and two autism-specific public schools have been in existence for more than 10 years. The autism-specific private and public 
schools were also chosen according to approximate their founding dates [autism-specific public school 1 (1973) and 2 (2004); autism-specific private school 3 (1975) and 4 (2006)] to make comparisons.

\section{Participants}

The participants in the study included four principals of the autism-specific public and private schools and 150 caregivers of learners attending the participating schools. Convenience sampling was used to select the participants as only principals and caregivers who completed informed consent forms and a questionnaire could participate.

All four participating principals were female South African citizens with a post-secondary attainment level of either a degree or a postgraduate teaching qualification. All four principals had more than 25 years of teaching experience. The majority of the 150 caregivers in both the autism-specific public $(86.5 \%)$ and private $(79.2 \%)$ schools were mothers. Furthermore, $50.8 \%$ of the mothers in the autism-specific public schools and $83.3 \%$ of the mothers in the autism-specific private schools had a post-secondary attainment level of either a diploma or a degree, or a postgraduate qualification.

\section{Data collection}

Different questionnaires were distributed to the principals and the caregivers. The first questionnaire was completed by the four principals and the second questionnaire was distributed to the caregivers of the 541 learners attending the four designated autism-specific schools. To establish the reliability and validity of the two questionnaires, the researchers conducted a pilot study in an autism-specific school. Fifteen caregivers and one principal completed and returned the pilot questionnaires, and the necessary changes were made. The questionnaire to the principals focussed on information about the school and included questions about when the school was established, age ranges of the learners, admission criteria of the school, school fees, therapeutic services offered by the school, number of learners the school can accommodate, number of learners currently attending the school, number of names on the waiting list, teacher-learner ratio and the principal's preference regarding IE and autismspecific education. The caregiver survey included questions about gender, population group, age of child when parent became concerned about development, age when diagnosed and when admitted to school. We received the self-completed questionnaires back from the four principals and a total of 150 (27.2\%) questionnaires from caregivers. Caregiver questionnaires were assigned to one of two groups according to the type of school the learner was attending: group 1 (public) $(n=126)$ and group 2 (private) $(n=24)$.

\section{Data analysis}

Comparisons between the two autism-specific public and two autism-specific private schools were descriptive in nature (questionnaire for principals). Data from the caregiver questionnaire were captured electronically and exported to IBM SPSS (Statistical Package for Social Sciences version 22) (IBM Corp 2013) for further analysis. Non-parametric tests, using a significance level of $p<0.05$, were used to explore the existence of significant differences among different variables.

\section{Ethical considerations}

Ethical Clearance was obtained from the University of Pretoria (Reference number: 28024967 [GW20160702HS]) and written permission from the Department of Basic Education and the principals of the autism-specific public and private schools. Informed consent was obtained from principals and the caregivers of learners attending the schools during 2017. The researchers maintained anonymity and confidentiality of the participants and their schools throughout the research process.

\section{Results}

The results are presented according to the study objectives. Firstly, differences and similarities in the profiles of the participating autism-specific schools are depicted in Table 1. Secondly, the profiles of learners, with specific reference to the early management of ASD, in group 1 and group 2 are explained.

\section{Profiles of participating autism-specific schools}

Table 1 presents the comparison between two autism-specific public and two autism-specific private schools in Gauteng.

As can be seen in Table 1 (1.1), two of the autism-specific schools (public school 1 and private school 4) were established during the apartheid era (1948-1994), and the other two autism-specific schools after the democratic change of government in SA. During the 1970s, children with disabilities were entirely excluded from the mainstream education system worldwide (Inclusion BC 2014). The change towards IE in high-income countries (HICs) began in the late 1980s (Inclusion BC 2014). However in LMICs, such as SA, the transformation to IE only began in the early 2000s when IE policies were formulated and implemented (DoE 1995, 1996, 1997, 2010a, 2010b, 2014; Margia, McConkey \& Myezwa 2014; UNESCO 1994). Our results show that even though legislation and policies stipulate that learners with disabilities, such as ASD, should be included in mainstream schools, the DoE is still establishing autism-specific schools, therefore perpetuating the IE legislation and policies (Evans 2016). Although there are no official statistics in SA, it seems that children with ASD are still placed in public and private special educational needs schools rather than in mainstream schools (ASA n.d.; DoE 2015; Pillay et al. 2017). Therefore, our results are in agreement with a systematic database study conducted in the Western Cape Province by Pillay et al. who found that of the 940 children with ASD enrolled in schools in that province, approximately $90 \%$ attended special education needs schools and only $10 \%$ were attending mainstream schools. A possible explanation might be that the educational 
implications of ASD are extensive and encompass many challenges for learners in mainstream schools. This also seems to be the trend in other countries such as Australia, the United Kingdom and the United States (Humphrey 2008:132; Roberts \& Simpson 2016:1093; Simpson, De Boer-Ott \& Smith-Myles 2003:130).

The autism-specific public schools accommodate very young and older learners (3-21 years), whereas the autism-specific private schools mostly accommodate learners only until the age of 10-11 years (see Table 1 [1.2]). Although the South African Schools Act (DoE 1996) compels children between the ages of 7 and 15 years to attend school, it seems that the autism-specific private schools do not accommodate learners older than 11 years. Therefore, learners attending the autismspecific private schools are often compelled to transition to other private special education needs schools or mainstream schools when they reach the school's age limit. Evidence suggests that learners with ASD experience significant and unique challenges in adjusting to new educational settings (Adreon \& Durocher 2007:271; Cheak-Zamora, Teti \& First 2015:557; Marsh et al. 2017:194). The learners experience enhanced anxiety levels when transitioning between schools which may be because of difficulty in dealing with new social situations, social communication and social interaction impairments, problems with adjusting to the new environment and responses to new sensory experiences (Hannah \& Topping 2012:207). To prevent unnecessary changes, it is imperative that educational services accommodate learners with ASD who are older than 11 years.

In both the autism-specific public and private schools, the children are screened and assessed by the school's multidisciplinary team to determine whether they are candidates for the school. Firstly, the admission criteria in both the autism-specific public and private schools required candidates to be diagnosed with ASD by a professional. Secondly, in the autism-specific public schools, caregivers

TABLE 1: Profiles of the participating autism-specific schools.

\begin{tabular}{|c|c|c|c|c|}
\hline \multirow[t]{2}{*}{ Schools } & \multicolumn{2}{|r|}{ Public } & \multicolumn{2}{|c|}{ Private } \\
\hline & 1 & 2 & 3 & 4 \\
\hline $\begin{array}{l}\text { 1.1 Date when schools were } \\
\text { established }\end{array}$ & 1973 & 2004 & 1975 & 2006 \\
\hline $\begin{array}{l}1.2 \text { Age ranges of learners in the } \\
\text { schools }\end{array}$ & $3-18$ & $3-21$ & $3-10$ & $2-11$ \\
\hline $\begin{array}{l}\text { 1.3 Admission requirements of the } \\
\text { schools }\end{array}$ & \multicolumn{2}{|c|}{$\begin{array}{l}\text { Child had to be diagnosed with ASD and caregivers had to be working or } \\
\text { living in the school's catchment area }\end{array}$} & \multicolumn{2}{|c|}{$\begin{array}{l}\text { Child had to be diagnosed with ASD } \\
\text { No limitations on where family lives }\end{array}$} \\
\hline $\begin{array}{l}\text { 1.5 Therapy services included in } \\
\text { school fees }\end{array}$ & $\begin{array}{l}\text { Speech-language therapy, } \\
\text { occupational therapy, } \\
\text { psychology services and } \\
\text { music therapy }\end{array}$ & $\begin{array}{l}\text { Speech-language therapy, occupational } \\
\text { therapy, psychology services, hippo } \\
\text { therapy and music therapy }\end{array}$ & $\begin{array}{l}\text { Speech-language therapy, } \\
\text { occupational therapy and } \\
\text { floortime therapy }\end{array}$ & $\begin{array}{l}\text { Speech-language } \\
\text { therapy (in groups) and } \\
\text { occupational therapy } \\
\text { (in groups) }\end{array}$ \\
\hline $\begin{array}{l}\text { 1.6 Number of learners the schools } \\
\text { can accommodate }\end{array}$ & 116 & 350 & 30 & 45 \\
\hline $\begin{array}{l}1.7 \text { Number of learners in the } \\
\text { schools at the time of data } \\
\text { collection }\end{array}$ & 116 & 350 & 12 & 41 \\
\hline $\begin{array}{l}1.9 \text { Number of teachers in the } \\
\text { schools }\end{array}$ & 14 & 45 & 2 & 5 \\
\hline 1.10 Teacher-learner ratio & $1: 7$ & $1: 7.5$ & $1: 6$ & $1: 8.2$ \\
\hline \multicolumn{5}{|l|}{ 1.11 Gender of learners in schools } \\
\hline \multicolumn{5}{|l|}{ Male } \\
\hline$n$ & 89 & 23 & 14 & 8 \\
\hline$\%$ & 88.1 & 92.0 & 93.3 & 88.9 \\
\hline \multicolumn{5}{|l|}{ Female } \\
\hline$n$ & 12 & 2 & 1 & 1 \\
\hline$\%$ & 11.9 & 8.0 & 5.7 & 11.1 \\
\hline Male-to-female ratio & $7.4: 1$ & $11.5: 1$ & $14.0: 1$ & $8.0: 1$ \\
\hline \multicolumn{5}{|l|}{$\begin{array}{l}1.12 \text { Population distribution of } \\
\text { learners in the schools }\end{array}$} \\
\hline \multicolumn{5}{|l|}{ Black } \\
\hline \multicolumn{5}{|l|}{ White } \\
\hline$n$ & 1 & 7 & 5 & 0 \\
\hline$\%$ & 0.99 & 30.4 & 33.3 & 0.0 \\
\hline \multicolumn{5}{|l|}{ Asian/Indian } \\
\hline$n$ & 1 & 1 & 2 & 1 \\
\hline$\%$ & 0.99 & 0.4 & 13.3 & 11.1 \\
\hline \multicolumn{5}{|l|}{ Mixed race } \\
\hline$n$ & 1 & 0 & 1 & 0 \\
\hline$\%$ & 0.99 & 0.0 & 6.6 & 0.0 \\
\hline
\end{tabular}


had to be working or living in the school's catchment area, whereas in the autism-specific private schools there were no limitations on where the family lives. Therefore, admission is determined by the caregivers' ability to pay the high monthly school fees. The admission criteria for autismspecific private schools differ from that of the autism-specific public schools as they are not accountable to the GDE in this regard (Basic education rights handbook, 2017, s. 27).

The results show that the monthly school fees in autismspecific private schools were significantly higher $(p<0.001)$, far more than double the amount than that of autism-specific public schools (see Table 1 [1.4]). A possible explanation may be that some private schools do not receive any subsidy from the government (Basic education rights handbook, 2017, s. 27). Furthermore, they are allowed to determine their school fees and rely on parents to pay these fees, endowments from the public and fundraising to cover their costs (Basic education rights handbook, 2017, s. 27). Our results are in agreement with a study conducted in Sweden who found that families raising children with ASD have significant costs related to their education (Jäbrink 2007:102).

Statistically significant differences were found when comparing the therapy services included in the school fees of the autism-specific public and private schools $(p<0.001)$. The results showed that even though the school fees in autismspecific private schools are higher than that of the autismspecific public schools, they offer fewer therapies that are included in the school fees. A reason could be that the allied health professionals, which include speech-language therapists, occupational therapists and psychologists, are employed by the GDE (Basic education rights handbook, 2017, s. 27). Therefore, the autism-specific public schools can offer a wider variety of therapeutic services. This may also be because allied health professionals usually work in private practice in SA and only offer their services at the autismspecific private schools, but are not employed by the school. According to the principals, the therapeutic services included in the autism-specific private schools' fees are usually limited to a few days per week or therapy is provided in groups. Learners requiring individualised therapy receive additional intervention either at school or in private practice, but caregivers are responsible for the costs. Future research is needed to determine the effectiveness of group therapy compared to individualised therapy for learners with ASD.

As can be seen in Table 1 (1.6-1.8), the autism-specific public schools can accommodate more learners than the autismspecific private schools. This is because autism-specific public schools have bigger buildings, while autism-specific private schools are usually housed in renovated houses. Although the autism-specific public schools can accommodate more learners, these schools are often overstretched (ASA n.d.). Both of the autism-specific public schools reported that at the time of data collection they had 16 names on the waiting list. The waiting lists could have been longer if the GDE did not open units for ASD in LSEN schools. On the contrary, the autism-specific private schools were able to accommodate a few more learners and were not overcapacity. The study by Pillay et al. (2017) also reported on the consolidated waiting list for children with ASD in the Western Cape Province. Therefore, although there were not as many names on the waiting list in Gauteng Province as in the Western Cape Province, there is a need to establish more educational services across SA to accommodate learners with ASD and to relieve the pressure on the existing schools and to reduce the teacher-learner ratios.

As was to be expected there were more teachers in the autismspecific public schools than in the autism-specific private schools (see Table 1 [1.9]). The teacher-learner ratio in both the autism-specific public and private schools was approximately the same $(p<0.910)$, ranging from 1:7 to 1:8.2. The teacher-learner ratio in autism-specific schools is lower than in mainstream schools because it has been widely reported that teaching one learner with ASD equals teaching six neurotypically developing learners (Clasquin-Johnson \& Clasquin-Johnson 2018:a357).

Although no statistically significant differences were found when comparing the gender of the learners in the autismspecific public and private schools $(p<0.739)$, the majority of learners in the sample were males (see Table 1 [1.11]). The findings show that the male-to-female ratio in the autismspecific public schools (6.8:1) and autism-specific private schools (8.0:1) did not differ greatly. However, the gender inequality in our study was higher than that reported in a population-based cohort study (2001-2011) conducted in Stockholm, Sweden, where the male-to-female ratio was 4:1 (Idring et al. 2014:1769). Male dominance may merely reflect the difficulty of diagnosing ASD in females (New, Triebwasser \& Charney 2008:654). Some variability in the ratio can be attributed to the clinical presentation of ASD, which is different in males in comparison to females, although available findings are inconsistent (Rivet \& Matson 2011:966). Females with an ASD diagnosis and high intelligence quotient (IQ) are perceived as being more social and have higher language abilities (Halladay et al. 2015:2). Therefore, the presentation of their symptoms may be misinterpreted, and an accurate diagnosis might be delayed (Halladay et al. 2015).

The majority of learners in both the autism-specific public $(89.7 \%)$ and private $(62.5 \%)$ schools were black, which is consistent with the racial demographics in SA (Statistics South Africa 2011). The results also show that significantly more $(p<0.001)$ learners in the autism-specific private schools were white $(25.0 \%)$ and Asian/Indian $(12.5 \%)$ than in the public schools (white $=6.4 \%$; Asian $/$ Indian $=1.5 \%$ ). A possible explanation why more white, Indian and Asian learners were able to attend the autism-specific private schools might be because they were able to afford the higher school fees. According to Statistics South Africa (2011), families from white, Indian and Asian population groups earn a higher average income than black families. 


\section{Profiles of learners attending the autism-specific schools}

Table 2 shows the differences and similarities in the profiles of learners, with specific reference to the early management of ASD, for group $1(n=126)$ and group $2(n=24)$.

Results in Table 2 (2.1) indicate that the mean age (in months) when caregivers became concerned about their child's development in the autism-specific public and private schools was similar $(p<0.590)$. The greater SD in the autism-specific private schools indicates that some caregivers became concerned about their child's development earlier than caregivers in autism-specific public schools. Furthermore, the differences in the post-secondary education attainment level of the mothers (group $1=83.3 \%$; group $2=50.8 \%$ ) might have had an influence on the age when mothers became concerned. US studies found that higher educational levels are associated with earlier age of identification (Fountain, King \& Bearman 2011:505; Goin-Kochel \& Myers 2005:441). Despite the differences in population groups, all caregivers in our study became concerned about their child's development later than in other studies (Werner et al. 2000:158; Young, Brewer \& Pattinson 2003:134). Studies on parental concerns about children who were later diagnosed with ASD have shown that caregivers from Australia and the United States were able to recognise atypical development between the ages of 8 and 12 months (Werner et al. 2000; Young et al. 2003). Our results show that caregivers may have limited knowledge about typical developmental milestones in young children and as a result were unable to identify developmental concerns at an early age (8-12 months). The findings also highlight the importance of supporting all caregivers by coordinated awareness raising and introducing early identification and intervention programmes for infants and young children with special needs.

No statistically significant differences were noted between the autism-specific public (on average 47.9 months) and private schools (on average 42.7 months) when considering the age of ASD diagnosis, but the mean age at diagnosis was later than in other studies conducted in SA $(p<0.368)$ (Springer et al. 2013:95). Results from our study are in close agreement with the age of ASD diagnosis (45-47 months) in LMICs such as Colombia, India, Jamaica, Jordan and Mexico
(Samms-Vaughan 2014:30). A population-based study in the United States found that ASD can now be reliably diagnosed on average at the age of 15-24 months (Guthrie et al. 2013:589). A possible explanation why learners in our study were diagnosed later could relate to delayed parental concerns about their child's development. Caregivers might have limited knowledge of typical developmental milestones, limited awareness of developmental disorders such as ASD and limited access to diagnostic services.

Although no statistically significant differences were found between the age when caregivers became concerned about their child's development and the mean age of ASD diagnosis, the results in Table 2 (2.3) indicated that significantly more $(p<0.015)$ children in the autism-specific private schools (29.2\%) were admitted to school before the age of 3.9 years than in the autism-specific public schools (9.5\%). Therefore learners in the autism-specific private schools started attending school earlier than learners in the autism-specific public schools. The earlier age at school admission in autismspecific private schools may relate to no waiting lists and because the admission criteria of the private schools stipulate that they already accommodate children with ASD from the age of $2-3$ years. Furthermore, it could be that caregivers of learners in the autism-specific private schools were able to afford the high monthly school fees and therefore enrol their child in autism-specific private schools without having to wait for placement. Evidence suggests that early intervention for children with ASD are predictors of success in intervention (Corsello 2005:81). It is therefore important that children with ASD are enrolled in ECE and early intervention programs as early as possible (Peters-Sheffer et al. 2012:1770). If children are to benefit from early childhood education and early intervention, it is essential that ASD is identified and diagnosed at an early age.

\section{Principals' preferences towards the inclusion of learners with autism spectrum disorder in mainstream schools}

Of the four schools, only one principal indicated that she preferred that learners with ASD be included in mainstream schools. This principal was of the opinion that learners with

TABLE 2: Profiles of learners in group $1(n=126)$ and group $2(n=24)$.

\begin{tabular}{|c|c|c|c|c|c|c|c|c|}
\hline \multirow[t]{3}{*}{ Characteristic } & \multirow[t]{3}{*}{ Category } & \multicolumn{6}{|c|}{ Frequency } & \multirow[t]{3}{*}{ Significance $p$} \\
\hline & & \multicolumn{3}{|c|}{ Group 1} & \multicolumn{3}{|c|}{ Group 2} & \\
\hline & & $n$ & $\%$ & SD & $n$ & $\%$ & SD & \\
\hline \multirow{3}{*}{$\begin{array}{l}2.1 \text { Age (months) when caregivers became } \\
\text { concerned about child's development }\end{array}$} & $<47$ months & 120 & 95.2 & - & 24 & 100.0 & - & 0.590 \\
\hline & $>48$ months & 6 & 4.8 & - & 0 & 0.0 & - & \\
\hline & Mean age (in months) & 26.2 & - & 10.0 & 26.3 & - & 15.2 & \\
\hline \multirow{3}{*}{$\begin{array}{l}\text { 2.2 Age (months) when child was diagnosed } \\
\text { with ASD }\end{array}$} & $<47$ months & 76 & 60.3 & - & 17 & 70.8 & - & 0.368 \\
\hline & $>48$ months & 50 & 39.7 & - & 7 & 29.2 & - & \\
\hline & Mean age (in months) & 47.9 & - & 25.2 & 42.7 & - & 10.7 & \\
\hline \multirow{3}{*}{$\begin{array}{l}2.3 \text { Age (years) when child was admitted } \\
\text { to autism-specific school }\end{array}$} & $<3.9$ years & 12 & 9.5 & - & 7 & 29.2 & - & $0.015 *$ \\
\hline & $>4.0$ years & 114 & 90.5 & - & 17 & 70.8 & - & \\
\hline & Mean age (in years) & 5.7 & - & 1.9 & 4.1 & - & 1.1 & \\
\hline
\end{tabular}

SD, standard deviation; ASD, autism spectrum disorder.

*, Statistically significant association $(p<0.05)$. 
ASD will benefit from socially interacting with their typically developing peers, and show improved behaviour and academic performance (Kasari \& Rotherham-Fuller 2007). In contrast, the other three principals preferred that learners with ASD be placed in separate autism-specific schools. Reasons given included that teachers are currently not adequately trained to support learners with ASD in typical classrooms and these learners often experience difficulty adapting in mainstream schools because they present with significant challenges in behaviour, social interaction and communication. The principals reported that there is an overall lack of support and training for teachers working with learners with ASD in mainstream schools and that there are many challenges related to IE policy implementation. Furthermore, learners with ASD often experience difficulty in adapting to mainstream schools because their behaviour is markedly different from that of typically developing peers. Also, learners with ASD may show particular interaction challenges in the classroom and a lack of theory of mind which may include low tolerance of their peer group, little or no empathy for others and dislike taking turns (Lamers \& Hall 2003:94). Learners with ASD often present with communication challenges that are amplified in the classroom. The communication challenges include limited conversational skills, lack of communicative intent and limited understanding of the attempts of others (Lord 2000:393). Lastly, behavioural challenges displayed by learners with ASD are sometimes even more severe in the classroom than at home (Lord \& Corsello 2014:96). Behavioural problems often include difficulties with the rigidity of thought, pretend play, repetitive play patterns and understanding the cause and effect of their behaviour (Lord \& Corsello 2014). Our results are in agreement with early studies conducted before the full IE implementation in the United States, which found that principals prefer that learners with ASD be placed schools for special education needs instead of mainstream schools (Cook, Semmel \& Gerber 1999:206; Praisner 2003:141). Our findings are in support of a study from SA that reported that there are many barriers related to the inclusion of learners with disabilities in mainstream schools. The preferences of principals from mainstream schools and other autism-specific schools towards IE of learners with ASD should be investigated further in SA, as such research may help identify factors that contribute the successful inclusion of learners with ASD and point to the support needs of all stakeholders. A recent study in Australia found that successful inclusion of learners with ASD is possible if all stakeholders receive adequate training, structural support, resources and funding from the government and if a collaborative approached is followed in the education process (Roberts \& Simpson 2016:1084).

\section{Limitations of the study}

The study is subject to a few limitations. Firstly, the researchers relied solely on information obtained from the questionnaires completed by the caregivers of the learners in autism-specific public and private schools. Although data obtained from the questionnaires were not confirmed with the caregivers and principals through interviews, it should be noted that selfcompleted questionnaires are less biased than interviews. Furthermore, the participating schools were situated in urban Gauteng areas only, and therefore only a small sample was recruited for the study. Lastly, there was a low response rate from caregivers.

\section{Implications or recommendations}

Data obtained from this study can be used as reference for future studies to track changes in ASD education trends in SA or similar countries. Such research may improve early ASD management, determine how many children with ASD are in the mainstream and special educational needs schools and identify how to better support learners, caregivers, teachers and principals in autism-specific schools. Also, homeschooling for learners with ASD should be further investigated. It is important to promote targeted awareness about ASD among the general public by developing ongoing ASD information training programmes. The successful inclusion of learners with ASD and principals' preferences towards the inclusion of learners with ASD in mainstream schools should be investigated further in SA. It is essential that autism-specific public and private schools provide full service and mainstream schools with training and resources so that learners with ASD receive quality education. If older children are accommodated and school fees are reduced, more families will be able to afford to pay the school fees. Lastly, more educational services accommodating learners with ASD should be established in SA to relieve the pressure on the existing schools and to accommodate other children with ASD who are not receiving the ongoing specialised education they need.

\section{Conclusion}

In this article, we focussed on comparing the differences between autism-specific public and private schools. It is evident that the autism-specific public schools make by far the greatest contribution to education learners with ASD. Our results support the recent progress report on the implementation of WP6, which indicated that some children with disabilities, including ASD, are not receiving the specialised education they need (DoE 2015). Consequently, there is a need to establish more educational services accommodating learners with ASD in SA, but this does not necessarily imply segregated placement. Instead, learners with ASD should be placed in schools according to their level of severity and therefore meeting their educational needs. Overall, it is encouraging to note that both the public and private autism-specific schools in SA are now providing education to racially diverse children in SA. As a result of limited space in autism-specific public schools and minimal progress in IE for learners with ASD, some similarities were also found in the learner profiles across the different types of schools than differences. The results indicated that children in both public and private autism-specific schools were not benefiting from ECE. It seems that late identification sets a trajectory of late intervention. Therefore, if children are to benefit from ECE, it is essential that children with ASD is 
identified and diagnosed earlier than indicated in our study. Factors underlying the trajectory may be that caregivers were unfamiliar with early ASD symptoms, and the fact that there are limited diagnostic services and schools for children with ASD. It is important to focus on creating awareness about ASD among the general public by developing systematic training programmes. Lastly, the findings showed that principals preferred that learners with ASD should be placed in separate autism-specific schools rather than being included in mainstream schools. The current findings, therefore, highlight the need to determine the barriers that hinder IE of learners with ASD in SA.

\section{Acknowledgements}

The authors would like to thank the anonymous reviewers for their generous time and insightful comments.

\section{Competing interests}

The authors declare that they have no financial or personal relationships that may have inappropriately influenced them in writing this article.

\section{Authors' contributions}

S.E. was the primary author and compiled the complete document based on doctoral degree research. A.K. was the supervisor and provided continuous input and internal review of this article. J.v.d.L. was the co-supervisor and provided continuous input and internal review of this article.

\section{Funding information}

This research was funded by the University of Pretoria Postgraduate Bursary.

\section{Data availability statement}

Data are available upon request from the corresponding author.

\section{Disclaimer}

The views and opinions expressed in this article are those of the authors and do not necessarily reflect the official policy or position of any affiliated agency of the authors.

\section{References}

Adreon, D. \& Durocher, J.S., 2007, 'Evaluating the college transition needs of individuals with high-functioning autism spectrum disorders', Intervention in School and Clinic 42(5), 271-279. https://doi.org/10.1177/10534512070420050201

American Psychiatric Association, 2013, Diagnostic and statistical manual of mental disorders (DSM-5 $\left.{ }^{\oplus}\right)$, American Psychiatric Association, Washington, DC.

Autism South Africa (ASA), n.d., Autism government funded schools, viewed 27 May 2016, from http://aut2know.co.za/.

Basic education rights handbook, 2017, Section 27, Johannesburg, South Africa.

Bornman, J. \& Rose, J., 2010, Believe that all can achieve, Van Schaik, Pretoria.

Cheak-Zamora, N.C., Teti, M. \& First, J., 2015, 'Transitions are scary for our kids, and they're scary for us': Family member and youth perspective on the challenges of transitioning to adulthood with autism', Journal of Applied Research and Intellectual Disabilities 28(6), 548-560. https://doi.org/10.1111/jar.12150
Clasquin-Johnson, M.G. \& Clasquin-Johnson, M., 2018, 'How deep are your pockets? Autoethnographic reflections on the cost of raising a child with autism', African Journal of Disability 7(0), a356. https://doi.org/10.4102/ajod.v7i0.356

Cook, B.G., Semmel, M.I. \& Gerber, M.M., 1999, 'Attitudes of principals and special education teachers toward the inclusion of student with mild disabilities', Remedial and Special Education 20(4), 199-207. https://doi.org/10.1177/ 074193259902000403

Corsello, C.M., 2005, 'Early intervention in autism', Infants \& Young Children 18(2), 74-85. https://doi.org/10.1097/00001163-200504000-00002

Department of Education, 1995, White paper on education and training, Government Printer, Pretoria.

Department of Education, 1996, South African schools act, act 84 of 1996, Government Printer, Pretoria.

Department of Education, 1997, Integrated national disability strategy, Government Printer, Pretoria.

Department of Education, 2001, Education white paper 6. Special needs education: Building an inclusive education and training system, Government Printer, Pretoria.

Department of Education, 2010a, Guidelines for full service/inclusive schools, Government Printer, Pretoria.

Department of Education, 2010b, Guidelines for inclusive teaching and learning, Government Printer, Pretoria.

Department of Education, 2014, Policy on screening, identification, assessment and support (SIAS), Government Printer, Pretoria.

Department of Education, 2015, Report on the implementation of education white paper 6 on inclusive education, Government Printer, Pretoria.

Donohue, D. \& Bornman, J., 2014, 'The challenges of realising inclusive education in South Africa', South African Journal of Education 32(2), 1-14. https://doi. org/10.15700/201412071114

Engelbrecht, P., 2006, 'The implementation of inclusive education in South Africa after ten years of democracy', European Journal of Psychology of Education 21(3), 253-264. https://doi.org/10.1007/BF03173414

Evans, J., 2016, 'Gauteng rolling out schools for autistic children', News 24, viewed 12 May 2016, from https://www.news24.com/SouthAfrica/News/gauteng-rollingout-schools-for-autistic-children-20160512.

Fountain, C., King, M.D. \& Bearman, P.S., 2011, 'Age of diagnosis for autism Individual and community factors across 10 birth cohorts', Journal of Epidemiology \& Community Health 65(6), 503-510. https://doi.org/10.1136/ jech.2009.104588

Goin-Kochel, R.P. \& Myers, B.J., 2005, 'Parental report of early autistic symptoms: Differences in ages of detection and frequencies of characteristics among three autism spectrum disorders', Journal on Developmental Disabilities 11(2), 21-39.

Guthrie, W., Swineford, L.B., Nottke, C. \& Wetherby, A.M., 2013, 'Early diagnosis of autism spectrum disorder: Stability and change in clinical diagnosis and symptom presentation', Journal of Child Psychology and Psychiatry 54(5), 582-590. https:// doi.org/10.1111/jcpp.12008

Halladay, A.K., Bishop, S., Constantino, J.N., Daniels, A.M., Koenig, K., Palmer, K. et al., 2015, 'Sex and gender differences in autism spectrum disorder: Summarizing evidence gaps and identifying emerging areas of priority', Molecular Autism 6(36) 1-5. https://doi.org/10.1186/s13229-015-0019-y

Hannah, E. \& Topping, K.J., 2012, 'Anxiety levels in students with autism spectrum disorder making the transition from primary to secondary school', Education and disorder making the transition from primary to secondary school',
Training in Autism and Developmental Disabilities 47(2), 198-209.

Human Sciences Research Council, 2009, Western Cape department of socia development 2009: Audit of early childhood development facility quality, Human Sciences Research Council, Cape Town.

Humphrey, N., 2008, 'Including pupils with autistic spectrum disorders in mainstream schools', Support for Learning 23(1), 41-47. https://doi.org/10.1111/j.14679604.2007.00367.x

Idring, S., Lundberg, M., Sturm, H., Dalman, C., Gumpert, C., Rai, D. et al., 2015, 'Changes in prevalence of autism spectrum disorders in 2001-2011: Findings from the Stockholm youth cohort', Journal of Autism and Developmental Disorders 45(6), 1766-1773. https://doi.org/10.1007/s10803-014-2336-y

Inclusion BC, 2014, A parent's handbook on inclusive education, 5th edn., Inclusion $\mathrm{BC}, \mathrm{BC}$

Jäbrink, K., 2007, 'The economic consequences of autistic spectrum disorder among children in a Swedish municipality', Autism 11(5), 453-463. https://doi. org/10.1177/1362361307079602

Jones, A.P. \& Frederickson, N., 2010, 'Multi-informant predictors of social inclusion for students with autism spectrum disorders attending mainstream school', Journal of Autism and Developmental Disorders 40(9), 1094-1103. https://doi.org/ 10.1007/s10803-010-0957-3

Kasari, C. \& Rotheram-Fuller, E., 2007, 'Peer relationships of children with autism: Challenges and interventions', in E. Hollander \& E. Anagnostou (eds.), Clinical manual for the treatment of autism, pp. 235-258, American Psychiatric Publishing, Arlington, VA.

Lamers, K. \& Hall, L.J., 2003, 'The response of children with autism to preferred prosody during instruction', Focus on Autism and Other Developmental Disabilities 18(2), 93-102. https://doi.org/10.1177/108835760301800203

Lord, C., 2000, 'Commentary: Achievements and future directions for intervention research in communication and autism spectrum disorders', Journal of Autism and Developmental Disorders 30(5), 393-398. https://doi.org/10.1023/ A:1005591205002 
Lord, C. \& Corsello, C., 2014, 'Diagnostic instruments in autism spectrum disorders', in F.R. Volkmar, R. Paul, A. Klin \& D. Cohen (eds.), Handbook of autism and pervasive
developmental disorders, 3rd edn., pp. 730-771, John Wiley \& Sons Inc, Hoboken, NJ.

Margia, L., McConkey, L. \& Myezwa, H., 2014, 'Introduction', in L. Margia, L. McConkey \& H. Myezwa (eds.), Inclusive education in low-income countries: A resource book for teacher educators, trainers and community development workers, pp. 2-11, Atlas Alliance and Disability Innovations Africa, Cape Town, South Africa.

Marsh, A., Spagnol, V., Grove, R. \& Eapen, V., 2017, 'Transition to school for children with autism spectrum disorder: A systematic review', World Journal of Psychiatry 7(3), 184-196. https://doi.org/10.5498/wjp.v7.i3.184

New, A.S., Triebwasser, J. \& Charney, D.S., 2008, 'The case for shifting borderline personality disorder to Axis I', Biological Psychiatry Journal 64(8), 653-659. https://doi.org/10.1016/j.biopsych.2008.04.020

Nhlapo, Z., 2018, 'Why homeschooling is becoming more of an option for South Africans', Huffington Post, viewed 27 June 2018, from https://www.huffingtonpost. co.za/2018/01/25/why-homeschooling-is-becoming-more-of-an-option-forsouth-africans_a_23343216/.

Peters-Scheffer, N., Didden, R., Korzilius, H. \& Matson, J., 2012, 'Cost comparison of early intensive behavioral intervention and treatment as usual for children with autism spectrum disorder in the Netherlands', Research in Developmental Disabilities 33(6), 1763-1772. https://doi.org/10.1016/j.ridd.2012.04.006

Pillay, S., Duncan, M. \& De Vries, P., 2017, 'How many children with autism spectrum disorder (ASD) are there in South African schools: A systematic database search for known cases of ASD in the Western Cape Province', poster presented at the 2017 Africa Regional International Meeting for Autism Research, Stellenbosch, 7-9th September.

Praisner, C.L., 2003, 'Attitudes of elementary school principals towards the inclusion of students with disabilities', Exceptional Children 69(2), 135-145. https://doi. org/10.1177/001440290306900201

Republic of South Africa (RSA), 1996, Constitution of the Republic of South Africa, Government Printer, Pretoria.

Rivet, T.T. \& Matson, J.L., 2011, 'Review of gender differences in core symptomatology in autism spectrum disorders', Research in Autism Spectrum Disorders 5(3), 957-976. https://doi.org/10.1016/j.rasd.2010.12.003

Roberts, J. \& Simpson, K., 2016, 'A review of research into stakeholders perspectives on inclusion of students with autism in mainstream schools', International Journal ofInclusiveEducation20(10),1084-1096.https://doi.org/10.1080/13603116.2016. 1145267
Saloojee, G., Phohole, M., Saloojee, C. \& ljsselmuiden, C., 2006, 'Unmet health welfare and educational needs of disabled children in an impoverished South African peri-urban township', Child: Care, Health and Development 33(3), 230-235. https://doi.org/10.1111/j.1365-2214.2006.00645.x

Samms-Vaughan, M.E., 2014, 'The status of early identification and early intervention in autism spectrum disorders in lower- and middle-income countries', International Journal of Speech-Language Pathology 16(1), 30-35. https://doi.org/10.3109/17 549507.2013.866271

Simpson, R.L., De Boer-Ott, S.R. \& Smith-Myles, B., 2003, 'Inclusion of learners with autism spectrum disorders in general education settings', Topics in Language Disorders 23(2), 116-133. https://doi.org/10.1097/00011363-20030400000005

Springer, P.E., Van Toorn, R., Laughton, B. \& Kidd, M., 2013, 'Characteristics of children with pervasive developmental disorders attending a developmental clinic in the Western Cape Province, South Africa', South African Journal of Child Health 7(3), 95-99. https://doi.org/10.7196/sajch.530

Statistics South Africa, 2011, Census 2011, viewed 02 April 2018, from http://www. statssa.gov.za/publications/p03014/p030142016

Statistics South Africa, 2014, Census 2011: Profiles of persons with disabilities in South Africa, viewed 10 June 2018, from http://www.statssa.gov.za/?p=3180.

The Bill of Rights of the Constitution of the Republic of South Africa, 1996, Government Gazette. (No. 17678), Government Printer, Pretoria.

UNESCO, 1994, The Salamanca statement and framework for action on special needs education, UNESCO, Paris.

Waddington, E.M. \& Reed, P., 2017, 'Comparison of the effects of mainstream and special school placements on outcomes in children with ASD: An archive-based analysis', Journal of Research in Special Educational Needs 17(2), 132-142. analysis', Journal of Research in Special
https://doi.org/10.1111/1471-3802.12368

Werner, E., Dawson, G., Osterling, J. \& Dinno, N., 2000, 'Recognition of autism spectrum disorder before one year of age: A retrospective study based on home videotapes', Journal of Autism and Developmental Disorders 30(2), 157-162. https://doi.org/10.1023/A:1005463707029

Whitman, T.L., 2004, The development of autism: A self-regulatory perspective, Jessica Kingsley Publishers, London.

Young, R.L., Brewer, N. \& Pattison, C., 2003, 'Parental identification of early behavioural abnormalities in children with autistic disorder', Autism 7(2), 125-143. https:// doi.org/10.1177/1362361303007002002 